\title{
Phylogenetic Analysis of Phyllospadix iwatensis Based on Nucleotide Sequences Encoding 18S rRNA and ITS-1
}

\author{
Jong-Myoung Kim ${ }^{1 *}$ and ChangGeun $\mathrm{Choi}^{2}$ \\ ${ }^{1}$ Dept. of Marine Biomaterials and Aquaculture, and ${ }^{2}$ Dept. of Ecological Engineering, \\ Pukyong National University, Pusan 608-737, Korea
}

\begin{abstract}
Seagrasses are marine angiosperms of ecological importance in providing shelter and food to aquatic species as well as maintaining the carbon cycle on earth. Phyllospadix iwatensis is a seagrass of the family Zosteraceae and is distributed along the eastern coast of Korea. The nucleotide sequences of $P$. iwatensis nuclear genes encoding 18S ribosomal RNA (rRNA) and internal transcribed spacer-1 (ITS-1) were determined for molecular phylogenetic analysis. Genomic DNA was isolated from $P$. iwatensis and used for PCR amplification of 18S rRNA and ITS-1. Examination of the 18S rRNA sequence of $P$. iwatensis showed a close ( $99 \%$ similarity) relationship to Zostera noltii, another genus of Zosteraceae, but a distant ( $84 \%$ similarity) evolutionary relationship to other macroalgal Laminariales species. Further discrepancies found in ITS-1 nucleotide sequences between closely related species indicate that the sequence information could be used for species identification.
\end{abstract}

Key words: 18S rRNA, ITS-1, Phyllospadix, Phylogeny

\section{Introduction}

Seagrasses are unique marine flowering plants with long, narrow, and very often green leaves growing in marine environments. They are found anchored in sand or mud bottoms in shallow coastal areas and complete their entire life cycle underwater (Phillips and Menez, 1988). Seagrass beds play ecologically important roles by providing crucial habitats and food for various marine organisms from fish to mollusks and microalgae (Turner, 1985). Seagrass is also of interest for its high rates of primary production, contributing up to $15 \%$ of the ocean's total carbon storage as well as absorbing almost a quarter of global carbon emission (Williams, 1995). Therefore, from an ecological perspective, it is important to examine the species and populations of seagrasses distributed along coastlines.

Seagrasses belong to one of four plant families, Posidoniaceae, Zosteraceae, Hydrocharitaceae, and Cymodoceaceae, in the order Alismatales (Phillips and Menez, 1988). The family Zosteraceae is closely related to a family of freshwater aquatics, Potamogetonaceae, and contains approximately fourteen species divided into two genera, Phyllospadix and

\footnotetext{
*Corresponding author: jongkim@pknu.ac.kr
}

Zostera. The latter genus is further divided into three subgenera, Heterozostera, Zostera, and Zosterella. The genus Phyllospadix has been known as one of the seagrasses found in submerged coastal waters along the temperate North Pacific (Philips, 1979). The genus is morphologically characterized by the rhizome with congested internodes, marginal fin cell of the leaf, and dioecism (Tomlinson, 1982). Two species in the genus, $P$. iwatensis and $P$. japonica, are distributed along the coastline in Korea and Japan. Morphological differences between these two species include the apical shape of the leaf, the number of veins in the leaf, and the color of fibrous remains in the rhizome (Shin et al., 1993). P. iwatensis is characterized by a rounded apex, three and five veins in the apical and lower portions of the leaf, respectively, and brown fibrous remains in the rhizome (Kuo et al., 1990; Yabe et al., 1995). Although the morphological characteristics of $P$. iwatensis have been fairly well documented (Shin et al., 1993), little information has been available on its molecular markers and phylogenetic analysis. To perform phylogenetic analysis of Phyllospadix using molecular markers, nucleotide sequences of the regions encoding the 18s rRNA and ITS-1 of $P$. iwatensis were determined in this study. Comparisons of the 18S rRNA sequence with that of other species 
provided information on the evolutionary position of Phyllospadix, which is distant from other macroalgal species, but close to seagrasses. The nucleotide sequence of the ITS-1 region provides further information for species-specific identification of Phyllospadix.

\section{Materials and Methods}

\section{Materials}

Phyllospadix iwatensis was collected from the coastal areas of Uljin, Korea. Collected samples were stored at $-20^{\circ} \mathrm{C}$ until DNA isolation.

Restriction endonucleases were purchased from Bioneer (Daejeon, Korea). Kits used for plasmid purification, gel extraction, and PCR purification were purchased from NucleoGen (Seoul, Korea). The pGEM $^{\circledR}$-T Easy Vector system was obtained from Promega Corporation (Madison, WI). Oligonucleotides and a HiQ-PCR mix were obtained from Genotech (DaeJeon, Korea). The oligonucletides used for the amplification of 18s rRNA and ITS-1 were as follows: 5'-TCCGTAGGTGAACCTGCGG (ITS1F); 5'-GCTGCGTTCTTCATCGATGC (ITS1R), 5'-CAA CCTGGTTGATCCTGCCAGT (18SF); 5'-CTGATC CTTCTGCAGGTTCACCTAC (18SR).

\section{Isolation of genomic DNA}

Genomic DNA was isolated using the nuclei isolation/CTAB methods described in Valera-Alvarez (2006). A 0.5-g tissue sample was ground in a mortar in the presence of liquid nitrogen and homogenized in $5 \mathrm{~mL}$ STE buffer ( $400 \mathrm{mM}$ sucrose, $50 \mathrm{mM}$ Tris. $\mathrm{Cl}$ $\mathrm{pH}$ 7.8, $20 \mathrm{mM}$ EDTA, 0.2\% bovine serum albumin, and $0.2 \% \beta$-mercaptoethanol). The homogenate was filtered through a $50 \mu \mathrm{m}$ nylon mesh by squeezing and subjected to centrifugation at $1,000 \mathrm{x} g$ for $20 \mathrm{~min}$. The nuclei pellet, resuspended in $50 \mu \mathrm{L}$ of $\mathrm{CTAB}$ buffer ( $2 \%$ CTAB, $2 \%$ polyvinylpyrrolidone, $1.4 \mathrm{M}$ $\mathrm{NaCl}, 20 \mathrm{mM}$ EDTA, and $100 \mathrm{mM}$ Tris. $\mathrm{Cl} \mathrm{pH} 8.0$ ), was incubated at $65^{\circ} \mathrm{C}$ for $1 \mathrm{hr}$. The suspension was extracted with an equal volume of the mixture containing chloroform:isoamylalcohol (24:1) followed by centrifugation at $14,000 \mathrm{rpm}$ for $3 \mathrm{~min}$. DNA in the supernatant was precipitated by the addition of two volumes of ethanol and 0.1 volume of $3 \mathrm{M}$ sodium acetate $(\mathrm{pH}$ 5.2) followed by centrifugation. The DNA was examined by $0.7 \%$ agarose gel electrophoresis.

\section{Cloning of the genes encoding 18S rRNA and ITS-1}

Amplification of 18S rRNA and ITS-1 was carried out in $20 \mu \mathrm{L}$ of PCR mixture including HiQ-Mix
PCR mixture, and $0.1 \mu \mathrm{g}$ of isolated genomic DNA. The reaction was carried out with an initial denaturation at $95^{\circ} \mathrm{C}$ for $5 \mathrm{~min}$ followed by 30 cycles of $45 \mathrm{sec}$ at $94^{\circ} \mathrm{C}, 30 \mathrm{sec}$ at $55^{\circ} \mathrm{C}$ and $90 \mathrm{sec}(18 \mathrm{~S}$ rRNA) or $45 \mathrm{sec}$ (ITS-1) at $72^{\circ} \mathrm{C}$, with a final extension of $5 \mathrm{~min}$ at $72^{\circ} \mathrm{C}$. Amplified PCR products, resolved upon agarose gel electrophoresis, were purified by gel extraction, cloned into the pGEM $^{\circledR}-\mathrm{T}$ Easy vector, and then transformed into $E$. coli $\mathrm{DH} 5 \alpha$ as described by Sambrook et al. (2001). Recombinant plasmids were isolated using alkaline lysis and analyzed by restriction digestion and DNA sequencing.

\section{Sequence alignment and phylogenetic analysis}

The obtained nucleotide sequences were aligned with other rRNA and ITS sequences using Clustal W (Thompson et al., 1994). The NCBI GenBank accession numbers of the $18 \mathrm{~s}$ rRNA sequences examined in this study were as follows: Phyllospadix iwatensis (Phyliwat, GenBank HQ660595, this study), Zostera noltii (AF207058), Posidonia oceanica (AY491942), Potamogeton pusillus (EF526354), Ulva pertusa Kjellman (AB425961), Ecklonia cava Kjellman (AF123579), Agarum clathratum Dumortier (AF123576), Costaria costata Saunders (AB022819), Porphyra yezoensis Ueda (DQ666486), and Gelidium amansii (Lamouroux) Lamouroux (DQ316994). The NCBI GenBank accession numbers of the ITS-1 sequences examined in this study were as follows: Phyllospadix iwatensis (Phyliwat, HQ660596, this study), Zostera noltii (AF102275), Phyllospadix torreyi (AY077985), Ulva pertusa Kjellman (HM 485430), Ecklonia cava Kjellman (AF319009), Agarum clathratum Dumortier (FJ042768), Costaria costata Saunders (AF319027), and Panax japonica (HQ112433).

A phylogenetic tree was constructed using the neighbor-joining method in MEGA v 4.0 (Tamura et al., 2007). An assessment of tree reliability was conducted using a bootstrap method with 1000 replicates.

\section{Results and Discussion}

Aquatic plants and macroalgae distributed along coastlines are important for marine ecology due to their provision of shelter and food for aquatic species as well as their importance in maintaining global carbon storage and emission cycles. Phyllospadix, which is distributed along the coast of Korea and Japan, is a perennial seagrass belonging to the family Zosteraceae. Although the morphological charac- 
teristics and growth dynamics of Phyllospadix have been fairly extensively examined (Shin et al., 1993; Tomlinson, 1982; Park and Lee, 2009), little information is available on its detailed molecular characteristics and phylogenetic analysis. Ribosomal RNA has been used as one of the most common markers for analyzing the molecular phylogeny of macroalgae (Bird et al., 1992; Ragan et al., 1994), although its use has sometimes been known to be hindered by discrepancies due to the presence of duplicate copies. To carry out a molecular-markerbased phylogenetic analysis of $P$. iwatensis, DNA regions encoding 18S rRNA and its neighboring ITS sequences were analyzed for the first time in this study.

Isolation of high-quality genomic DNA from macroalgae and its use in PCR amplification have previously been hindered by the intractability of various algae to many DNA extraction procedures and the coextraction of polysaccharide and polyphenolic compounds, which can inhibit the processes (Varma et al., 2007; Koonjul et al., 1999). Methods have been described for the successful isolation of genomic DNA from various macroalgal species (Nakajima et al., 2000; Snirc et al., 2010; Hoarau et al., 2007). In this study, genomic DNA was isolated from ground Phyllospadix using the STE and CTAB buffer method (Valera-Alvarez, 2006). The quality of the isolated genomic DNA was confirmed by the presence of high-molecular-weight genomic DNA upon agarose gel electrophoresis (data not shown). PCR amplifications of the target genes were carried out using genomic DNA templates and primers deduced from the conserved sequences (Yotsukura et al., 1999). Amplification of the regions corresponding to $18 \mathrm{~S}$ rRNA and ITS-1 results in the synthesis of approximately $1.8 \mathrm{~kb}$ and $300 \mathrm{bp}$, respectively, fragments which are similar to the sizes of the corresponding regions in other macroalgal species including Ecklonia cava and Costaria costata (data not shown). Amplified fragments were purified from agarose gel, cloned into a pGEM-T vector, and then transformed into E. coli DH5 $\alpha$ (Sambrook et al., 2001). Recombinant plasmids were isolated from transformants and analyzed by EcoRI restriction digestion followed by agarose gel electrophoresis (data not shown).

Sequencing analysis of $18 \mathrm{~S}$ rRNA and ITS-1 clones showed the presence of 1,824- and $289 \mathrm{bp}$ fragments, including the regions corresponding to the primers (Fig. 1 and Fig. 2). Nucleotide sequences were obtained from at least two independent clones in which the sequences were confirmed by analysis from both directions. Analysis of $P$. iwatensis 18s rRNA using BlastN indicated the highest similarity to the $18 \mathrm{~s}$ rRNA of other seagrasses including Zostera noltii and Posidonia oceanica. P. iwatensis $18 \mathrm{~S}$ rRNA showed a $99 \%$ similarity to that of $Z$. noltii, another genus in Zosteraceae, and $98 \%$ similarity to that of $P$. oceanica, belonging to the family Posidoniaceae in the same order. Comparison of the 18s rRNA sequences of Agarum clathratum Dumortier and Costaria costata belonging to the same family, Laminariaceae, and Ecklonia cava Kjellman of the Alariaceae in the same order, Laminariales, showed almost completely identical $1.8 \mathrm{~kb}$ sequences, with divergence at only one position (data not shown). In contrast, the $18 \mathrm{~s}$ rRNA sequence of $P$. iwatensis showed only $84 \%$ similarity with those of macroalgal species belonging to Laminariceae. The results indicate a clear evolutionary distinction between seagrasses and other macroalgal species.

To further examine the phylogenetic differences among closely related species, DNA sequences encoding $P$. iwatensis ITS-1 with high variability were determined and compared with those of other members of the family Zosteraceae (Fig. 2). In contrast to the relatively highly conserved $18 \mathrm{~s}$ rRNA sequences, the ITS-1 fragments showed higher sequence variability in the region, as shown by an $87 \%$ similarity to that of $P$. torreyi and $70 \%$ similarity to that of $Z$. noltii. This provides useful information, not only for the detailed evolutionary analysis of $P$. iwatensis but also for its species-specific identification among closely related species.

Phylogenetic trees were constructed based upon $18 \mathrm{~S}$ rRNA and ITS-1 sequences of $P$. iwatensis (Fig. 3 and Fig. 4) compared with those of other macroalgae and seagrasses. Species belonging to the family Laminales were hardly distinguished by their almost identical 18srRNA sequences, as shown by Costaria costata, Agarum clathratum, members of the family Laminariaceae, and even Ecklonia cava, belonging to the neighboring family, Alariaceae, in the same order, Laminariales (Fig. 3). However, P. iwatensis 18S rRNA showed the closest, but distinguishable, evolutionary relationship with $Z$. noltii, another member of Zosteraceae. This was followed by Posidonia oceanica in the same order, Alismatales, and Potamogeton pusillus, a closely related but freshwater aquatic. These results were consistent with previous morphology-based classifi-cations and indicated that $18 \mathrm{~S}$ rRNA can be used to analyze the evolutionary relationships of Phyllospadix. The results also indicated that seagrasses are 
1 CAACCTGGTTGATCCTGCCAGTAGTCATATGCTTGTCTCAAAGATTAAGCCATGCATGTG 61 CAAGTATGAACTAATTCAGACTGTGAAACTGCGAATGGCTCATTAAATCAGTTATAGTTT 121 GTTTGATGGTACCTTGCTACTCGGATAACCGTAGTAATTCTAGAGCTAATACGTGCACCA 181 AACCCCGACTTCTGGAAGGGATGCATTTGTTAGATAAAAGGTTGACACGGGCCTTGTGCC 241 TGTTGCTCTGATGATTCATGATAACTTGACGGATCGCATGGCCTTTGTGCCGGCGACGCA 301 TCATTCAAATTTCTGCCCTATCAACTTTCGATGGTAGGATAGGGGCCTACCATGGTGGTG 361 ACGGGTGACGGAGAATTAGGGTTCGATTCCGGAGAGGGAGCCTGAGAAACGGCTACCACA 421 TCCAAGGAAGGCAGCAGGCGCGCAAATTACCCAATCCTGACACGGGGAGGTAGTGACAAT 481 AAATAACAATACCGGGCTCTTTGAGTCTGGTAATTGGAATGAGTACAATCTAAATCCCTT 541 AACGAGGATCCATTGGAGGGCAAGTCTGGTGCCAGCAGCCGCGGTAATTCCAGCTCCAAT 601 AGCGTATATTTAAGTTGTTGCAGTTAAAAAGCTCGTAGTTGGACCTTGGGTTGGGTCGGC 661 CGGTCCGCCTTATGGTGTGCACCGACCGTCTCGTCCCTTCTGCTGGTGATGCGTTCCTGT 721 CCTTAGTTGGTCGGGTCGTGCCTCCGGCGCTGTTACTTTGAAAGAAATTAGAGTGCTCAA 781 AGCAAGCCTATGCTCTGTATACATTAGCATGGGATAACATCACAGGATTTCGATCCTATT 841 TTGTTGGCCTTCGGGATCGGAGTAATGATTAAAAGGGACAGTCGGGGGCATTCGTATTTC 901 ATAGTCAGAGGTGAAATTCTTGGATTTATGAAAGACGAACAACTGCGAAAGCATTTGCCA 961 AGGATGTTTTCATTAATCAAGAACGAAAGTTGGGGGCTCGAAGACGATCAGATACCGTCC 1021 TAGTCTCAACCATAAACGATGCCGACCAGGGATTGGCGGATGTTGCTTTTAGGACTCCGC 1081 CAGCACCTTATGAGAAATCAAAGTTTTTGGGTTCCGGGGGGAGTATGGTCGCAAGGCTGA 1141 AACTTAAAGGAATTGACGGAAGGGCACCACCAGGAGTGGAGCCTGCGGCTTAATTTGACT 1201 CAACACGGGGAAACTTACCAGGTCCAGACATAGTAAGGATTGACAGATTGAGAGCTCTTT 1261 CTTGATTCTATGGGTGGTGGTGCATGGCCGTTCTTAGTTGGTGGAGCGATTTGTCTGGTT 1321 AATTCCGTTAACGAACGAGACCTCAGCCTGCTAACTAGCTATGCGGAGGTGACCCTTCGT 1381 GGCCAGCTTCTTAGAGGGACTATGGCCGCCTAGGCCACGGAAGTTTGAGGCAATAACAGG 1441 TCTGTGATGCCCTTAGATGTTCTGGGCCGCACGCGCGCTACACTGATGTATTCAACGAGT 1501 TTATAACCTTAGCTGATAGGCTTGGGTAATCTTTGAAAATTTCATCGTGATGGGGATAGA 1561 TCATTGCAATTGTTGGTCTTCAACGAGGAATTCCTAGTAAGCGTGAGTCATCAGCTCGCG 1621 TTGACTACGTCCCTGCCCTTTGTACACACCGCCCGTCGCTCCTACCGATTGAATGGTCCG 1681 GTGAAGTGCTCGGATTGTGGCGACGTTAGTGGTCTGCCGCTGGCGACGTCGTGAGAAGTC 1741 CACTGAACCTTATCATTTAGAGGAAGGAGAAGTCGTAACAAGGTTTCC GTAGGTGAACCT 1801 GCAGAAGGATCAG

Fig.1. Nucleotide sequence of $P$. iwatensis $18 \mathrm{~S}$ rDNA. Sequences corresponding to the primers used for PCR amplification are underlined.

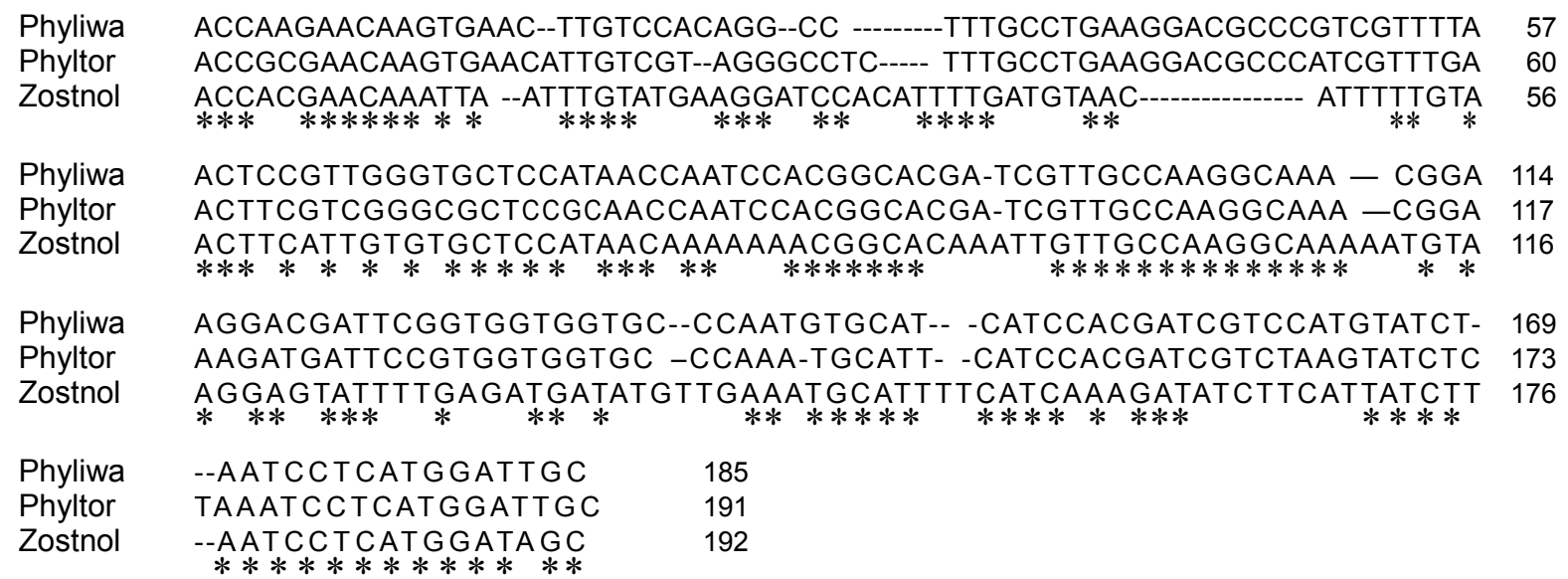

Fig. 2. Comparison of ITS-1 sequence of P. iwatensis to those of P. torreyi and Zostera noltii using Clustal W. Nucleotide sequences at the ends were trimmed to the same length for comparison.

phylogenetically closer to the species in Chlorophytae (Ulva pertusa) than to the species in Divisions Rhodophyta and Phaeophyta.
Phylogenetic analysis was also carried out using ITS-1 as a molecular marker (Fig. 4). The results showed the closest relationship to another member in 


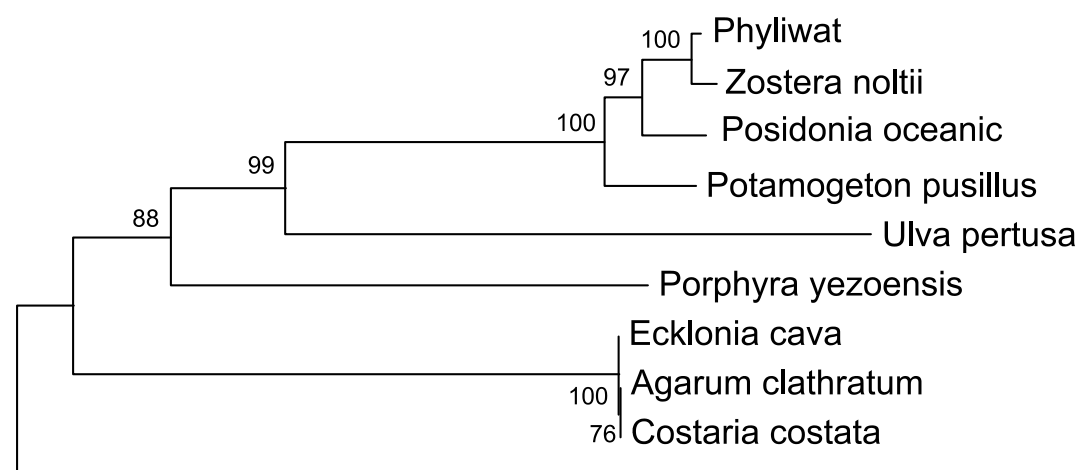

Gelidium amansii

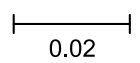

Fig. 3. Phylogenetic analysis of macroalgal species by using $18 \mathrm{~S}$ rDNA nucleotide sequence. Compared sequences include 18S rDNA of P. iwatensis (Phyliwat, HQ660595, this study), Zostera noltii (AF207058), Posidonia oceanica (AY491942), Potamogeton pusillus (EF526354), Ulva pertusa Kjellman (AB425961), Ecklonia cava Kjellman (AF123579), Agarum clathratum Dumortier (AF123576), Costaria costata Saunders (AB022819), Porphyra yezoensis Ueda (DQ666486), and Gelidium amansii (Lamouroux) Lamouroux (DQ316994).

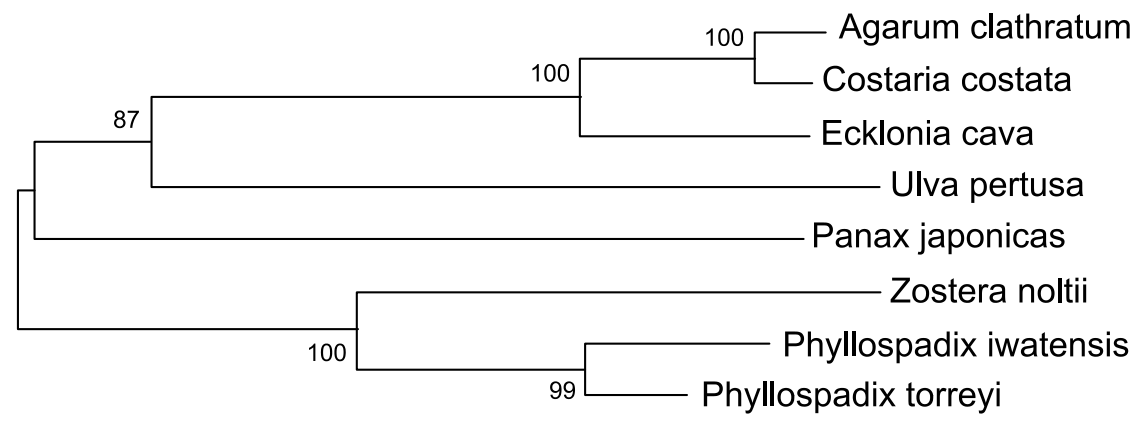

$$
\longmapsto
$$

Fig. 4. Phylogenetic analysis of macroalgae using nucleotide sequences encoding ITS-1. Accession numbers of sequences corresponding to ITS-1 regions searched from NCBI GenBank were as follows: P. iwatensis (Phyliwat, HQ660596, this study), Zostera noltii (AF102275), Phyllospadix torreyi (AY077985), Ulva pertusa Kjellman (HM485430), Ecklonia cava Kjellman (AF319009), Agarum clathratum Dumortier (FJ042768), Costaria costata Saunders (AF319027), and Panax japonica (HQ112433).

the genus, $P$. torreyi, followed by $Z$. noltii, another member of the same family. In particular, the evolutionary relationships among members of the order Laminariales (E. cava, A. clathratum, and C. costata), which were indistinguishable using $18 \mathrm{~S}$ rRNA markers, were clearly differentiated using ITS1 comparison. In addition, the evolutionary position of $P$. iwatensis was further distinguished from $P$. torreyi, in the same genus, and Zostera noltii, in the same family, showing a clear distinction between $P$. iwatensis and other seagrasses.

In summary, nucleotide sequences encoding $18 \mathrm{~s}$ rRNA and ITS-1 of $P$. iwatensis were obtained and used for a molecular phylogenetic analysis of $P$. iwatensis. The results provide information on the phylogenetic relationship between $P$. iwatensis and species of evolutionarily distant macroalgae, as well as closely related seagrasses. The information obtained will also be helpful for species-specific identification.

\section{Acknowledgements}

This research was supported by a grant from the Development of Marine-Bioenergy Program funded by the Ministry of Land, Transport and Maritime 
Affairs of the Korean Government.

\section{References}

Bird CJ, Murphy CA, Rics EL and Ragan MA. 1992. The $18 \mathrm{~S}$ rRNA gene sequences of four commercially important seaweeds. J Appl Phycol 4, 379-84.

Hoarau G, Coyer JA, Stam WT and Olsen JL. 2007. A fast and inexpensive DNA extraction/purification protocol for brown macroalgae. Mol Ecol Notes 7, 191-3.

Koonjul PK, Brandt WF, Farrant JM and Lindsey GG. 1999. Inclusion of polyvinylpyrrolidone in the polymerase chain reaction reverses the inhibitory effects of polyphenolic contamination of RNA. Nucl Acids Res 27, 915-6.

Kuo J, Iizumi H, Njelsen BE and Aioi K. 1990. Fruit anatomy, seed germination and seedling development in the Japanese seagrass Phyllospadix (Zosteraceae). Aquatic Bot 45, 53-62.

Nakajima M, Kitade Y, Iitsuka O, Fukuda S and Saga N. 2000. Rapid extraction of high-quality genomic DNA from Porphyra yezoensis (Bangiales, Rhodophyta). Phycol Res 48, 15-7.

Park JI and Lee K-S. 2009. Peculiar growth dynamics of the surfgrass Phyllospadix japonicus on the southeastern coast of Korea. Mar Biol 156, 2221-33.

Philips RC. 1979. Ecological notes on Phyllospadix (Potamogetonaceae) in the Northeast Pacific. Aquatic Bot 6, 159-70.

Phillips RC and Menez EG. 1988. Seagrasses. Smithsonian Contrib Mar Sci 34, 1-104.

Sambrook J and Russell DW. 2001. Molecular cloning: A laboratory manual. 3rd edition. Cold Spring Harbor Laboratory Press, NY, Plainview.

Shin HC, Oh YS and Choi HK. 1993. Taxonomic examination of Korean seagrasses I: Morphology and distribution of the genus Phyllospadix (Zosteraceae). Kor J Plant Tax 23, 189-99.

Snirc A, Silberfeld T, Bonnet J, Tillier A, Tuffet S, Tillier A, Tuffet S and Sun JS. 2010. Optimization of DNA extraction from brown algae (Phaeophyceae) based on a commercial kit. J Phycol 46, 616-21.

Tamura K, Dudley J, Nei M and Kumar S. 2007. MEGA4: Molecular Evolutionary Genetics Analysis (MEGA) software version 4.0. Mol Biol Evol 24, 1596-9.

Thompson JD, Higgins DG and Gibson TJ. 1994. CLUSTAL W: Improving the sensitivity of progressive multiple sequence alignment through sequence weight matrix choice. Nucleic Acids Res 22, 4673-80.

Tomlinson PB (1982) Anatomy of the Monocotyledons VII. Helobiae (Alismatidae). Clarendon Press. Oxford.

Turner T. 1985. Stability of rocky intertidal surfgrass beds; persistence, preemption, and recovery. Ecology 66, 8392.

Valez-Alvarez E, Andreakis N, Lago-Leston A, Pearson G, Serrao EA, Procaccini G, Duarte CM and Marba N. 2006. Genomic DNA isolation from green and brown algae (Caulerpales and Fucales) for microsatellite library construction. J Phycol 42, 741-745.

Varma A, Padh H and Shrivastava N. 2007. Plant genomic DNA isolation : an art or a science. Biotechnol J 2, 38692.

Williams SL 1995. Surfgrass (Phyllospadix torreyi) reproduction: reproductive phenology, resource allocation, and male parity. Ecology 76, 1953-70.

Yabe T, Ikusima I and Tsuchiya T. (1995) Production and population ecology of Phyllospadix iwatensis Makino. I Leaf growth and biomass in an intertidal zone. Ecol Res 10, 291-9.

Yotsukura N, Denboh T, Motomura T, Horiguchi T, Coleman AW and Ichimura T. 1999. Little divergence in ribosomal DNA internal transcribed spacer-1 and -2 sequences among non-digitate species of Laminaria (Phaeophyceae) from Hokkaido, Japan. Phycol Res 47, 71-80.

(Received 3 November 2010; Revised 30 November 2010; Accepted 13 December 2010) 